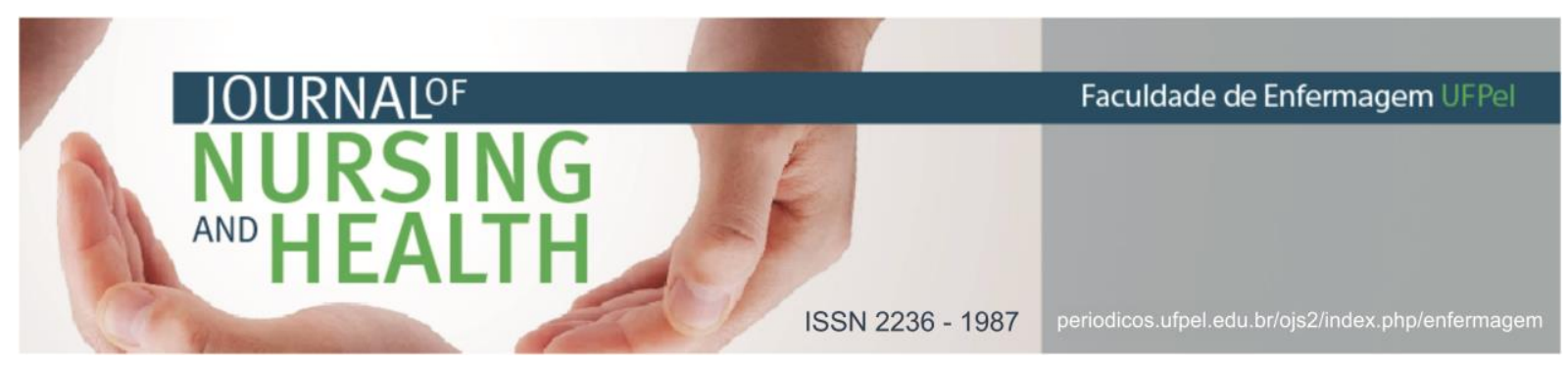

REVISÃO INTEGRATIVA

\title{
Características das lesões em acidentes motociclísticos: uma revisão integrativa da literatura
}

\author{
Types of injuries in motorcycle accidents: an integrative review of literature
}

\section{Características de las lesiones en accidentes de motocicleta: una revisión integrativa de la literatura}

Albrecht, Cristiane Carla ${ }^{1}$; Fávero, Débora Cristina ${ }^{2}$; Pegorin, Talita Cristina ${ }^{3}$; Fransceschi, Fabiane $^{4}$; Moser, Gelson Aguiar da Silva ${ }^{5}$

Como citar este artigo: Albrecht CC, Fávero DC, Pegorin TC, Fransceschi F, Moser GAS. Características das lesões em acidentes motociclísticos: uma revisão integrativa da literatura. J nurs health. 2018;8(3):e188303

\section{RESUMO}

Objetivo: conhecer as lesões ocorridas em acidentes motociclísticos no Brasil. Métodos: revisão integrativa cujas buscas foram realizadas em novembro de 2016 com os descritores motocicletas; acidente de trânsito; ferimentos e lesões. Resultados: 13 publicações foram encontradas na Literatura Latino-Americana e do Caribe em Ciências da Saúde e 337 na Medical Literature Analysis and Retrieval System Online, e após serem usados os critérios de seleção, restaram seis artigos. Podese perceber que as lesões predominam em membros superiores e inferiores, em homens jovens, durante o período da tarde e noite, sendo mais evidenciados na sexta-feira e no sábado. Considerações finais: o público mais acometido, as características das lesões mais frequentes e informações importantes relacionadas, foram identificadas neste estudo, as quais podem auxiliar no planejamento e desenvolvimento de estratégias a fim de diminuir esses altos índices de ocorrências. Descritores: Motocicletas; Acidentes de trânsito; Ferimentos e lesões.

\section{ABSTRACT}

Objective: to determine the types of injuries caused by motorcycle accidents in Brazil. Methods: an integrative review study carried out in November of 2016 with the descriptors motorcycles; traffic accidents; wounds and injuries. Results: 13 publications were found in Latin American and Caribbean Health Sciences Literature and 337 in Medical Literature Analysis and Retrieval System Online, and after applying the selection criteria, six articles remained. It can be seen that the lesions predominate in upper and lower limbs in young men during the afternoon and evening, being more evident on Friday and Saturday. Final considerations: the most affected patients, the characteristics of the most frequent lesions and important related information were identified in this study, which can help in the planning and development of strategies in order to reduce these high incidence rates.

Descriptors: Motorcycles; Accidents, traffic; Wounds and injuries.

1 Estudante de Enfermagem. Universidade Federal da Fronteira Sul (IFFS). E-mail: cristianecarlaalbrecht@hotmail.com http: //orcid.org/0000-0001-7385-6430

2 Estudante de Enfermagem. Universidade Federal da Fronteira Sul (IFFS). E-mail: deboracfavero@hotmail.com https: / /orcid.org/0000-0001-9541-713X

3 Estudante de Enfermagem. Universidade Federal da Fronteira Sul (IFFS). E-mail: talita_pegorin@hotmail.com https://orcid.org/0000-0001-8990-7888

4 Estudante de Enfermagem. Universidade Federal da Fronteira Sul (IFFS). E-mail: fai.franceschi@gmail.com https: / / orcid.org/0000-0001-9768-301X

5 Enfermeiro. Doutor em Enfermagem. Universidade Federal da Fronteira Sul (IFFS). E-mail: gelson.silva@uffs.edu.br https://orcid.org/0000-0001-9337-1684 


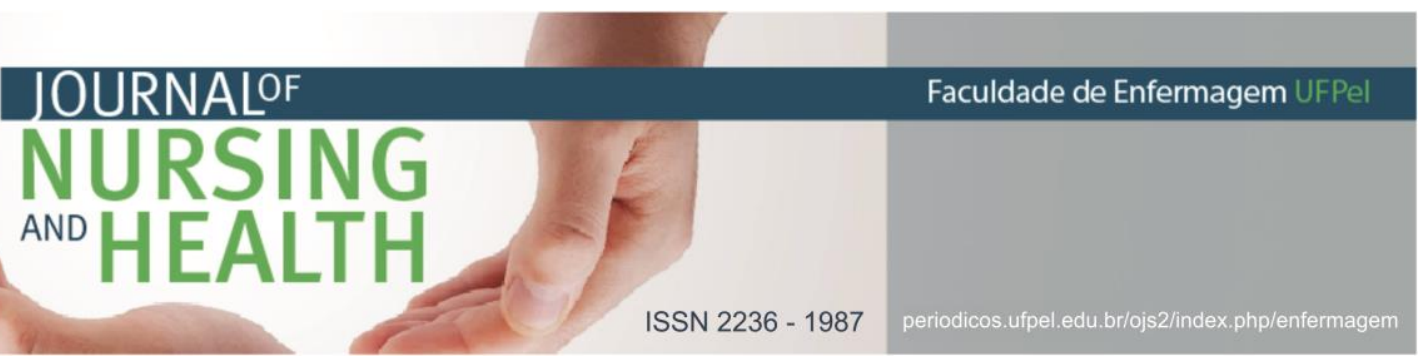

RESUMEN

Objetivo: conocer las lesiones sufridas en accidentes de motocicleta en Brasil. Métodos: revisión integrativa cuyas búsquedas se realizaron en noviembre de 2016 con los descriptores de las motocicletas; accidente de tránsito; lesiones y lesiones. Resultados: 13 publicaciones fueron encontradas en la Literatura Latinoamericana y del Caribe en Ciencias de la Salud y 337 en el Medical Literature Analysis and Retrieval System Online, y después de usar los criterios de selección, restaron seis artículos. Se puede percibir que las lesiones predominan en miembros superiores e inferiores, en hombres jóvenes, durante el período de la tarde y la noche, siendo más evidenciados el viernes y el sábado. Consideraciones finales: el público más acometido, las características de las lesiones más frecuentes e informaciones importantes relacionadas, fueron identificadas en este estudio, las cuales pueden auxiliar en la planificación y desarrollo de estrategias a fin de disminuir esos altos índices de ocurrencias.

Descriptores: Motocicletas; Accidentes de tránsito; Heridas y lesiones.

\section{INTRODUÇÃO}

0 uso da motocicleta tem aumentado visto a agilidade que a mesma proporciona ao usuário e também pela aquisição no mercado, devido ao seu custo de compra, impulsionado pelo aumento da população e frota em grandes centros urbanos. ${ }^{1}$ Este aumento em conjunto com o crescimento de profissões, que utilizam desse meio para trabalhar, podem estar relacionados a elevação do número de acidentes no trânsito, apoiando os altos índices de lesões, de diversos tipos e gravidade causando muitas vezes, incapacitações físicas e elevados índices de mortalidade. ${ }^{2}$

Os acidentes de trânsito em sua grande maioria estão associados a diversos fatores, como a própria inadequação na conservação de veículos, na precariedade das vias, nas falhas humanas, e também relacionadas ao consumo de substâncias psicoativas, nesse caso, por exemplo, o uso de álcool. ${ }^{3}$

Portanto os acidentes ocasionam danos sociais, físicos e psicológicos. Esses usuários de motocicletas, são vítimas de danos que podem variar de lesões temporárias até lesões permanentes e muitas vezes essas lesões são causas de invalides, mortes, absenteísmo no trabalho e responsáveis por um tempo de hospitalização prolongada, ocasionando um alto custo para os serviços de saúde. ${ }^{4}$

Entre as lesões que ocorrem em decorrência de acidentes motociclísticos prevalecem as escoriações e os ferimentos cortocontusos, sendo que essas lesões predominam nos membros superiores e inferiores. ${ }^{5}$ Anualmente registra-se no mundo cerca de 1,2 milhão de mortes decorrentes de acidentes de trânsito, representando 3 mil mortes/dia. ${ }^{6}$

Ações preventivas podem ser executadas por meio de educação em saúde, possibilitando a população repensar seus comportamentos de risco, enfatizando o uso de equipamentos de segurança como o capacete, calçados fechados, roupas que cubram a maior parte do corpo e principalmente respeitar as normas de trânsito. ${ }^{7}$

Desta forma, esses motivos influenciaram no interesse para o desenvolvimento deste estudo, o qual 


\section{NURSING \\ ${ }^{\text {ANO HEALTH }}$}

ISSN 2236 - 1987

possui o objetivo de conhecer as lesões ocorridas em acidentes motociclísticos no Brasil.

\section{MATERIAIS E MÉTODOS}

Trata-se de um estudo de revisão integrativa ao qual foi desenvolvido após etapas pré-determinadas. ${ }^{8}$ Para iniciar a pesquisa, foram definidos 0 tema, os objetivos, os descritores e a pergunta da pesquisa, relacionadas com os tipos de lesões que ocorrem em acidentes motociclísticos. A pergunta da pesquisa foi: Quais são os tipos das lesões ocorridas em acidentes motociclísticos no Brasil?

Conforme apresentado na Figura 1 , foram realizadas as buscas no mês de novembro de 2016, nas bases de dados do Sistema Online de Busca e
Análise de Literatura Médica (MEDLINE) e da Literatura Latino-Americana do Caribe em Ciências da Saúde (LILACS). Utilizou-se os seguintes descritores: "motocicletas"; "acidente de trânsito"; "lesões e ferimentos", os quais foram consultados nos Descritores da Ciência da Saúde (DeCS). Foram utilizados como critérios de inclusão artigos científicos produzidos por brasileiros, estudos que tratem da proposta desta pesquisa mesmo que a análise da divisão do trabalho não seja o objetivo do estudo, publicações no idioma português, textos completos e gratuitos disponíveis na íntegra e publicados entre junho de 2006 a junho de 2016. Quanto aos critérios de exclusão, optou-se por não utilizar teses, dissertações, editoriais, cartas, protocolos e livros.

Figura 1. Fluxograma de identificação, seleção e inclusão dos estudos para o desenvolvimento da pesquisa.

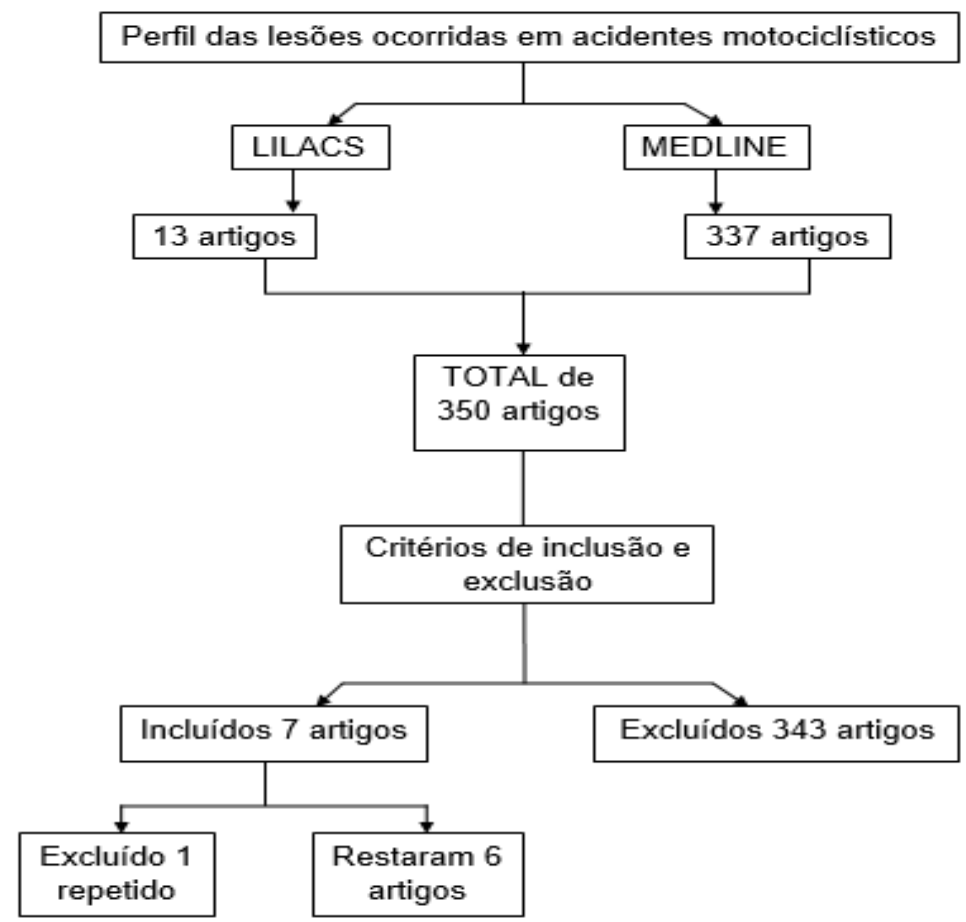




\section{JOURNALOF \\ AND}

NURSING
Através desses descritores foram encontrados 350 artigos (13 artigos na LILACS e 337 na MEDLINE), porém após serem usados os critérios de inclusão e exclusão foram excluídos 343 artigos restaram sete artigos relacionados diretamente com o tema, porém dois eram repetidos restando apenas seis artigos.

As buscas e a análise dos artigos foram realizadas pelos autores. Primeiramente iniciou-se a análise dos títulos e resumos com a aplicação de critérios de exclusão e inclusão de dados sobre artigos em planilha eletrônica com auxílio do software Microsoft Excel 2010 (nome do artigo, indicação de inclusão ou exclusão, motivos da exclusão).

Após, foram analisados os textos completos, através da leitura dos artigos incluídos no estudo em seguida, realizada a tabulação das publicações encontrados em planilha eletrônica estruturada com auxílio do software Microsoft Excel 2010 para exclusão de artigos duplicados e elaboração dos resultados.

\section{RESULTADOS E DISCUSSÃO}

Os artigos utilizados foram publicados na Revista Acta Fisiátrica, ${ }^{9}$ Revista Acta Ortopédica Brasileira, ${ }^{10}$ Revista Caderno Saúde Pública, ${ }^{11}$ Revista da Escola de Enfermagem da USP12, Revista Gaúcha de Enfermagem. ${ }^{13-14}$ Sendo publicados no ano de 2006, ${ }^{14} 2008,{ }^{11-13} 2010^{10}, 2011,9$ 2012, ${ }^{12}$ conforme mostra a Figura 2.

A partir da análise dos estudos, o artigo $\mathrm{A} 1^{9}$ investigou as principais características dos sobreviventes de acidentes de moto, o $A 2^{10}$ procurou
ISSN 2236 - 1987

avaliar os pacientes que deram entrada para atendimento no Pronto Socorro de Ortopedia e Traumatologia, evidenciando o tipo de acidente, tipo da lesão, localização anatômica, tempo de experiência dos acidentados e correlacionar as lesões encontradas com a velocidade no momento do trauma e com o uso dos equipamentos de segurança, $0 \quad A 3^{11}$ buscou caracterizar as vítimas de trauma por acidente de moto. 0 artigo $\mathrm{A} 4^{12}$ procurou evidenciar os fatores associados ao risco de lesões dos motociclistas que se envolveram em ocorrências de trânsito, já $0 \quad A 5^{13}$ estudou a relação entre as lesões mais frequentes observadas nas vítimas de acidentes de motocicleta e $0 \mathrm{A6}^{14}$ caracterizou os motociclistas vítimas de acidente de trânsito internados.

0 estudo $A 2^{10}$ nos traz os seguintes dados em relação aos tipos de lesões, 39,8\% correspondem a ferimentos, $31,1 \%$ a contusões e $15,8 \%$ a fraturas. Já no artigo $A 3,{ }^{11}$ segundo a distribuição do tipo de lesão sofrida; 70,2\% apresentaram ferimentos, 51,6\% apresentaram fraturas e $27,5 \%$ hematomas (Nota dos autores: Soma maior que $100 \%$, devido às respostas múltiplas).

$0 \mathrm{~A} 2^{10}$ traz na porcentagem das fraturas expostas $5,7 \%$ e nas fraturas fechadas $15,8 \%$, já o $A 3^{11}$ traz $51,4 \%$ nas fraturas em geral, o $A 5^{13} 22,60 \%$ nas fraturas de membros inferiores e nas de membros superiores $8,90 \%$, o A6 $6^{14}$ relata que $34 \%$ das fraturas ocorreram em membros inferiores, $22 \%$ em membros superiores, $18 \%$ na cabeça, $9 \%$ no quadril, $6 \%$ no abdômen, $6 \%$ no tórax e $5 \%$ na coluna. Em relação ao trauma cranioencefálico (TCE), o 
$A 3^{11}$ apresenta $20,7 \%$ e o $A 5^{13} 6,17 \%$. Em relação às contusões o $A 2^{10}$ traz $31,8 \%$ enquanto o A5 $8,90 \%$ em membros inferiores e $5,48 \%$ em membros superiores. Nas entorses o $\mathrm{A} 2^{10}$ expõe que $1,7 \%$ apresentam e no $A 5^{13} 4,48 \%$ mas somente em membros inferiores.

Figura 2: Caracterização dos estudos quanto aos autores, título, periódico e ano da publicação em relação a MEDLINE e LILACS.

\begin{tabular}{|c|c|c|c|c|}
\hline Periódico & $\begin{array}{c}\text { Ano de } \\
\text { Publicação }\end{array}$ & Autoria & Título & Código \\
\hline $\begin{array}{l}\text { Revista Acta } \\
\text { Fisiátrica }\end{array}$ & 2011 & $\begin{array}{c}\text { Soraia Dornelles } \\
\text { Schoeller; Albertina } \\
\text { Bonetti; Gelson Aguiar } \\
\text { da Silva; André Rocha, } \\
\text { Francine Lima } \\
\text { Gelbcke; Patricia Khan }\end{array}$ & $\begin{array}{l}\text { 1- Características das vítimas } \\
\text { de acidentes motociclísticos } \\
\text { atendidas em um centro de } \\
\text { reabilitação de referência } \\
\text { estadual do sul do Brasil }\end{array}$ & $\mathrm{A} 1^{9}$ \\
\hline $\begin{array}{l}\text { Revista Acta } \\
\text { Ortopédica } \\
\text { Brasileira }\end{array}$ & 2010 & $\begin{array}{l}\text { Pedro Debieux; Carla } \\
\text { Chertman; Nacime } \\
\text { Salomão Barbachan } \\
\text { Mansur; Eiffel Dobashi; } \\
\text { Helio Jorge Alvachian } \\
\text { Fernandes }\end{array}$ & $\begin{array}{c}\text { 2- Lesões do aparelho } \\
\text { locomotor nos acidentes com } \\
\text { motocicleta }\end{array}$ & $A 2^{10}$ \\
\hline $\begin{array}{l}\text { Revista Caderno } \\
\text { Saúde Pública }\end{array}$ & 2008 & \begin{tabular}{|c|} 
Ana Maria Ribeiro dos \\
Santos; Maria Eliete \\
Batista Moura; \\
Benevina Maria Vilar \\
Teixeira Nunes; Clara \\
Francisca dos Santos \\
Leal; João Batista \\
Mendes Teles
\end{tabular} & $\begin{array}{l}\text { 3- Perfil das vítimas de } \\
\text { trauma por acidente de moto } \\
\text { atendidas em um serviço } \\
\text { público de emergência }\end{array}$ & $\mathrm{A}^{11}$ \\
\hline $\begin{array}{c}\text { Revista da Escola } \\
\text { de Enfermagem da } \\
\text { USP }\end{array}$ & 2012 & $\begin{array}{c}\text { Nelson Luiz Batista de } \\
\text { Oliveira; Regina } \\
\text { Marcia Cardoso de } \\
\text { Sousa }\end{array}$ & $\begin{array}{c}\text { 4- Risco de lesões em } \\
\text { motociclistas nas ocorrências } \\
\text { de trânsito }\end{array}$ & $\mathrm{A} 4^{12}$ \\
\hline $\begin{array}{c}\text { Revista Gaúcha de } \\
\text { Enfermagem }\end{array}$ & 2008 & \begin{tabular}{|c} 
Aline de Oliveira \\
Pinto; Regina Rigatto \\
Witt
\end{tabular} & $\begin{array}{c}\text { 5- Gravidade de lesões e } \\
\text { características de } \\
\text { motociclistas atendidos em } \\
\text { um hospital de pronto socorro }\end{array}$ & $A 5^{13}$ \\
\hline $\begin{array}{c}\text { Revista Gaúcha de } \\
\text { Enfermagem }\end{array}$ & 2006 & \begin{tabular}{|c|} 
Andréa Márian \\
Veronese; Dora Lúcia \\
Leidens Correa de \\
Oliveira; Thaís dos \\
Santos Donato Shimitz
\end{tabular} & $\begin{array}{c}\text { 6- Caracterização de } \\
\text { motociclistas internados no } \\
\text { hospital de pronto-socorro de } \\
\text { Porto Alegre }\end{array}$ & $A 6^{14}$ \\
\hline
\end{tabular}

Fonte: MEDLINE e LILACS, 2018 


\section{JOURNALOF \\ NURSING \\ AND HEALTH}

ISSN 2236 - 1987

$\mathrm{Na}$ literatura encontramos o grau das lesões ocorridas, as quais predominam as lesões de menor gravidade. ${ }^{15}$ Ainda segundo o mesmo autor, o tipo de lesão mais frequente em $33,9 \%$ da pesquisa, foi corte/perfuração/laceração, e as fraturas em 20,7\% dos casos. ${ }^{15} \mathrm{Em}$ nosso estudo em relação a gravidade das lesões o artigo $\mathrm{A}^{1}{ }^{9}$ aponta que $61,05 \%$ apresentam lesões muito graves e extremamente graves, sendo que as lesões consideradas extremamente graves são traumatismos crânio encefálicos e traumas raquimedulares e correspondem a $12,15 \%$ do total de agravos, as lesões muito graves são consideradas pelo estudo as amputações de membros, que representam 48,9\% do total de agravos, dentre essas 94,6\% são amputações de membros inferiores. As lesões graves são representadas por fraturas de membros inferiores, as moderadas pelos membros superiores e as leves são fraturas diversas e luxações. ${ }^{9}$ Entretanto, no artigo $\mathrm{A} 5^{13}$ a maior incidência foi de lesões intermediárias que correspondem a $45,6 \%$, por conseguinte as lesões leves $34,4 \%$ e as lesões graves $20,0 \%$.

Em referência a distribuição das lesões pelo corpo, 0 artigo $A 2^{10}$ demonstra que as lesões de membros inferiores são as mais frequentes, com $53,9 \%$ sendo que $19,1 \%$ são no joelho, $9,7 \%$ no tornozelo, $8,5 \%$ na perna e $7,4 \%$ no pé, em seguida aparecem as lesões de membro superior com $41,1 \%$, destas, $9,6 \%$ na mão, $8,4 \%$ no ombro e $8,2 \%$ no cotovelo, logo após vem o segmento cefálico com $3,1 \%$ e coluna com 2,8\%. A localização das fraturas concentrava-se: $16 \%$ nos ossos do pé, $15,1 \%$ no fêmur, $12,7 \%$ no tornozelo,
$11,8 \%$ nos ossos da mão, $9,4 \%$ no punho, 7,5\% na clavícula e 16\% distribuídas nos demais ossos. $0 \mathrm{~A} 3^{11}$ diz que a maioria das vítimas possuía mais de uma área do corpo com lesão, algumas chegando até com cinco áreas lesadas, as áreas com maior proporção de lesões foram os membros inferiores com 55\%, a face com 52,2\%, os membros superiores $48,1 \%$ e a cabeça com $47,89 \%$. Já o artigo $A 5^{13}$ as lesões foram configuradas por região, sendo que membros inferiores e quadril corresponderam a 45,90\%, membros superiores $20,54 \%$, superfície externa $19,86 \%$, tórax $6,85 \%$, cabeça e pescoço $6,16 \%$ e face $0,69 \%$.

Das pessoas feridas nos acidentes, $76 \%$ eram os próprios condutores das motocicletas, e em $18,1 \%$ suspeitava-se o uso de álcool. ${ }^{16}$ 0 artigo $A 4^{12}$ nos trouxe a associação dos acidentes motociclísticos com outras variáveis. Em relação às mulheres $56,24 \%$ eram as condutoras e $43,76 \%$ as passageiras, já os homens $93,72 \%$ eram os condutores. Houve associação considerável entre os motociclistas com ferimentos e o número de veículos envolvidos, 68,34\% com dois veículos envolvidos, quanto ao tipo de acidente moto contra carro/camionete representou 54,43\% e o tipo de impacto abalroamento transversal ficou com a maior porcentagem $\quad 37,26 \%$ Em contrapartida, o número de motociclistas feridos foi maior quando estiveram envolvidos um e dois veículos e menor, nos casos de três ou mais veículos. A presença de ferimento mostrou associação com o sexo, pois o masculino ficou com $77,83 \%$ e o feminino com $22,17 \%$. A posição no veículo e a presença de ferimento 


\section{IOURNALOF \\ NURSING \\ AND 느는}

ISSN 2236 - 1987

também foi significativa, $83,52 \%$ para os condutores e $16,48 \%$ para os passageiros.

0 perfil de acidentes motociclísticos envolveu principalmente população masculina jovem com pouca experiência de condução e baixo nível de escolaridade. ${ }^{17}$ Outro estudo também constatou maiores índices de acidentes em jovens de 20 a 29 anos. ${ }^{15}$

Existe uma prevalência de ocorrer mais acidentes motociclísticos na sexta-feira, seguido de domingo e segunda-feira, predominantemente no período vespertino seguido do período noturno e matutino. ${ }^{17} \mathrm{Em}$ uma pesquisa realizada em 2013 observou-se mais acidentes na sexta-feira e no sábado, sendo que o período do dia que mais ocorrem acidentes é à tarde e à noite. ${ }^{15}$

A associação entre a ingestão de bebida alcoólica e trânsito é significativa, uma vez que é reconhecido como uma das causas mais frequentes de acidentes fatais. ${ }^{18}$

Os acidentes estão ocorrendo por causas de desobediência às normas de trânsito, e em períodos que não ocorrem maior fiscalização, uma estratégia que poderia ser utilizada para redução de casos de acidentes é a intensificação da fiscalização de trânsito em horários alternativos, horários estes que compreenderiam o final de semana e períodos noturnos.

\section{CONCLUSÃO}

Os acidentes de trânsito constituem-se como um problema de saúde pública, e estão relacionados com diversos fatores, sendo que estes corroboram para índices consideráveis de lesões e ferimentos, os quais precisam ser evidenciados a fim de promover estratégias que possam implicar na minimização dos riscos das lesões ocasionadas a partir de acidentes motociclísticos.

Observa-se ao longo da pesquisa que as publicações utilizadas pelo estudo, avaliaram parâmetros diversificados em relação às características das lesões ocorridas a partir de acidentes motociclísticos, dificultando análise comparativa entre os mesmos. Cada estudo utilizou diferentes populações com diversas características.

Constatou-se no decorrer do mesmo que as principais lesões evidenciadas foram localizadas em membros inferiores e superiores, predominantes em homens jovens, ocorridas durante o período da tarde e noite, mais evidenciados na sexta-feira e no sábado.

Nesse sentido, este estudo buscou conhecer as características das lesões mais predominantes nos acidentes de trânsito com motocicletas, com o intuito de contribuir com estratégias de saúde pública que venham ao encontro de realizar ações de prevenção buscando a sensibilização dos motociclistas e ações que auxiliem na assistência prestada a esse público.

\section{REFERÊNCIAS}

1 Machado RC, Lindau LA, Obelheiro M. Caracterização do uso de motocicletas como meio de transporte urbano em Porto Alegre. LUME repositório digital; 2014. 
2 Miziara ID, Miziara CSMG, Rocha LE. Acidentes de Motocicletas e sua relação com o trabalho: revisão da literatura. Saúde, ética e justiça [Internet]. 2014 [acesso em 2018 out 5];2(19):52-9. Disponível em: http://www.revistas.usp.br/sej/articl e/view/100092

3 Nunes MN, Nascimento LFC. Análise espacial de óbitos por acidentes de trânsito, antes e após a Lei Seca, nas microrregiões do estado de São Paulo. Rev assoc med bras [Internet]. 2012[acesso em 2018 Out 5];6(58):685$90 . \quad$ Disponível em: http://www.scielo.br/scielo.php?pid= S010442302012000600013\&script $=$ sci abstract\&tlng=pt

4 Petenuti A, Lopes L, Volpato RJ, Pessini MA. Caracterização das sequelas das vítimas de acidentes de trânsito com motocicletas em vias urbanas numa cidade da região noroeste do Paraná. Akrópolis [Internet]. $2016 \mathrm{jul} / \mathrm{dez}$ [acesso em 2018 out 5];2(24):131-42. Disponível em:

http://revistas. unipar.br/index.php/a kropolis/article/view/6332/3449

5 Simoneti FS et al. Padrão de vítimas e lesões no trauma com motocicletas. Rev fac ciênc méd sorocaba [Internet]. 2016 [acesso em 2018 out 5];18(1):3640. Disponível

em: http://revistas. pucsp.br/index.php/R FCMS/article/view/24711

6 World Health Organization (WHO). Global Status Report on Road Safety Time for action. [Internet]. 2018 [cited 2018 Oct 5]. Available from: http://www.who.int/violence_injury prevention/road_safety_status/report /en/
7 Rodrigues APB, Santos AMR, Machado DG, Moura MEB. Caracterização dos acidentes motociclísticos atendidos pelo serviço de atendimento móvel de urgência. Rev enferm UFPI [Internet]. 2014 [acesso em 2018 out 5];3(3):73-8. Disponível em: http://www.ojs.ufpi.br/index.php/re ufpi/article/view/2038/pdf

8 Cooper HM. Scientific guidelines for conducting integrative research reviews. Rev educ res [Internet]. 1982 [cited 2018 Oct 6]; 52(2):291-302. Availaible from: http:/ / journals.sagepub.com/doi/abs /10.3102/00346543052002291?journal Code=rera

9 Schoeller SD, Bonetti A, Silva GA, Rocha A, Gelbcke FL, Khan P. Características das vítimas de acidentes motociclisticos atendidas em um centro de reabilitação de referência estadual do sul do Brasil. Acta fisiatra [Internet]. 2011 [acesso em 2018 out 6];18(3):141-5. Disponível em:

http://www.revistas.usp.br/actafisiat rica/article/view/103641

10 Debieux $P$, Chertman C, Mansur NSB, Dobashi E, Fernandes HJA. Lesões do aparelho locomotor nos acidentes com motocicleta. Acta ortop bra [Internet]. 2010 [acesso em 2018 out 6];18(6):353-6. Disponível em: http://www.redalyc.org/articulo.oa?i $\mathrm{d}=65715772010$

11 Santos AMR, Moura MEB, Nunes BMVT, Leal CFS, Teles JBM. Perfil das vítimas de trauma por acidente de moto atendidas em um serviço público de emergência. Cad saúde pública [Internet]. 2008 [acesso em 2018 out 6];24(8):1927-38. Disponível em: 
http://www.scielo.br/scielo.php?scrip $\mathrm{t}=\mathrm{sci}$ arttext\&pid=S0102-

$311 \times 2008000800021$

12 Oliveira NLB, Sousa RMC. Risco de lesões em motociclistas nas ocorrências de trânsito. Rev esc enferm USP [Internet]. 2012 [acesso em 2018 out 6];46(5):1133-40. Disponível em: http://www.scielo.br/scielo.php?scrip $\mathrm{t}=$ sci_abstract\&pid $=$ S008062342012000 $500014 \& \operatorname{lng}=p t \& n r m=i s \& t$ lng=pt

13 Pinto AO, Witt RR. Gravidade de lesões e características de motociclistas atendidos em um hospital de pronto socorro. Rev gaúcha enferm [Internet]. 2008 set [acesso em 2018 out 5];29(3):408-14. Disponível em:

https://seer.ufrgs.br/RevistaGauchad eEnfermagem/article/view/6762

14 Veronese AM, Oliveira DLLC, Shimitz TSD. Caracterização de motociclistas internados no hospital de prontosocorro de Porto Alegre. Rev gaúcha enferm [Internet]. 2006 set [acesso em 2018 out 6];27(3):379-85. Disponível em:

https://seer.ufrgs.br/RevistaGauchad eEnfermagem/article/view/4627

15 Golias ARC, Caetano R. Acidentes entre motocicletas: análise dos casos ocorridos no estado do Paraná entre julho de 2010 e junho de 2011. Ciênc saúde coletiva [Internet]. 2013 [acesso em 2018 out 5];5(18):1235-46. Disponível em: http://www.scielo.br/scielo.php?scrip $\mathrm{t}=\mathrm{sci}$ arttext\&pid=S1413812320130005 00008

16 Legay LF, Santos SA, Lovisi GM, Aguiar JS, Borges KC, Mesquita RM, et al. Acidentes de transporte envolvendo motocicletas: perfil epidemiológico das vítimas de três capitais de estados brasileiros, 2007. Epidemiol serv saúde [Internet]. 2012 [acesso em 2018 out 6];2(21):283-92. Disponível em: http://scielo.iec.gov.br/scielo.php?sc ript=sci_arttext\&pid=S1679497420120 00200011

17 Zabeu JLA, Zovico JRR, Pereira Júnior WN, Tucci Neto PF. Perfil de vítima de acidente motociclístico na emergência de um hospital universitário. Rev bras ortop. [Internet]. 2013 [acesso em 2018 out 5];48(3):242-5. Disponível em: http://www.scielo.br/scielo.php?pid= s010236162013000300242\&script $=$ sci_a rttext\&tlng=pt

18 Silva BJC, Santos JDM, Santos AMR, Madeira MZA, Gouveia MTO. Acidentes com motocicletas: características da ocorrência e suspeita do uso de álcool. Cogitare enferm [Internet]. 2017 [acesso em 2018 out 6];3(22):e50715. Disponível em: https://revistas.ufpr.br/cogitare/arti cle/view/50715/pdf

Data de submissão: 23/09/2017

Data de aceite: 08/07/2018

Data de publicação: 09/11/2018 